\title{
Comparison of Different Treatment Methods for Idiopathic Sudden Sensorineural Hearing Loss
}

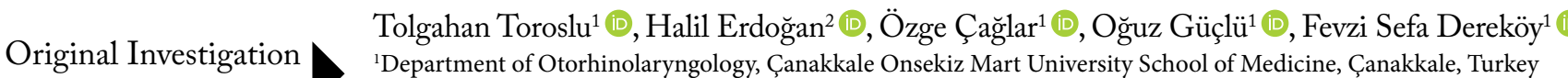 \\ ${ }^{1}$ Department of Otorhinolaryngology, Çanakkale Onsekiz Mart University School of M
${ }^{2}$ Department of Otorhinolaryngology, Elazı̆g Kovancılar State Hospital, Elazı̆g, Turkey
}

\section{Abstract}

ORCID IDs of the authors: T.T. 0000-0003-3280-8533; H.E. 0000-0002-7110-9631; Ö.C. 0000-0001-8737-2891; 0.G. 0000-0002-7351-3400; S.D. 0000-0002-7037-8901.

Cite this article as: Toroslu T, Erdoğan $\mathrm{H}$, Çăglar 0̈, Güçlü O, Dereköy FS. Comparison of Different Treatment Methods for Idiopathic Sudden Sensorineural Hearing Loss. Turk Arch Otorhinolaryngol 2018; 56(4): 226-32.

This study was presented at the 38th Turkish National Congress of Otorhinolaryngology Head and Neck Surgery, October 26-30, 2016, Antalya, Turkey.

Corresponding Author:

Tolgahan Toroslu; tolgahantoroslu@gmail.com

Received Date: 31.01.2017

Accepted Date: 31.03 .2017

Available Online Date: 21.12.2018

(c) Copyright 2018 by 0fficial Journal of the Turkish Society of Otorhinolaryngology and Head and Neck Surgery Available online at www.turkarchotolaryngol.net

DOI: $10.5152 /$ tao.2017.2337
Objective: To evaluate the effectiveness of different therapies for idiopathic sudden sensorineural hearing loss and prognostic factors, and determine the most successful treatment according to the audiogram type and time from onset to treatment.

Methods: A total of 90 cases from February 2009 to January 2015 were classified under Group I oral treatment (methylprednisolone, acyclovir, betahistine-dihydrochloride, and vitamin B12); Group II oral treatment + intratympanic steroids (ITS); Group III oral treatment + hyperbaric oxygen; and Group IV only ITS. A pure tone average (PTA) improvement of less than $10 \mathrm{~dB}$ was assessed as "no improvement," a PTA of $10 \mathrm{~dB}$ or more or a $10 \%$ or more increase in the speech discrimination score (SDS) as "partial improvement," and a hearing threshold within $10 \mathrm{~dB}$ and SDS within 5\%-10\% of the unaffected ear as "full improvement."

Results: Overall, $32.2 \%$ patients showed full and $28.9 \%$ showed partial improvement, whereas $38.9 \%$

\section{Introduction}

Idiopathic sudden sensorineural hearing loss (ISSNHL) is widely defined as the sensorineural hearing loss of $30 \mathrm{~dB}$ or more over at least three consecutive frequencies within less than three days (1). The incidence of ISSNHL is reported to be 5-20 in 100,000 (2). Of the cases that present to outpatient clinics for otological reasons 2-3\% are reported to be diagnosed with ISSNHL (3). ISSN$\mathrm{HL}$ can be encountered in every age group but is mostly seen in the $4^{\text {th }}$ to $6^{\text {th }}$ decades $(3,4)$. The maleto-female ratio is almost equal (5). In $90-98 \%$ of the cases ISSNHL involves only one ear $(3,6,7)$.

Its exact etiology is still not clear, and a specific cause can be identified in only $10 \%$ of the patients $(5,8)$. Today, studies on the etiopathogenesis of showed no improvement. There was no significant difference in terms of mean hearing gain between the different treatment methods. As the degree of hearing loss and time from onset to treatment increased, improvement worsened $(p<0.05)$. Descending audiogram had lower mean hearing gains compared to other groups $(p=0.014)$. There was no significant effect of age, sex, tinnitus and/or vertigo, and systemic disease on treatment success $(p>0.05)$.

Conclusion: The most important factors affecting prognosis were the time from onset to treatment, hearing loss severity, and audiogram type. Only ITS avoided side effects and reduced hospitalization. ITS in the first two weeks, followed by hyperbaric oxygen were considered as the treatment priority.

Keywords: Sudden hearing loss, steroids, hyperbaric oxygen therapy, intratympanic injection
ISSNHL suggest viral infection of the cochlea, vascular causes (thrombus, vasospasm, embolism), autoimmune diseases and cochlear membrane disorders, among which viral diseases and vascular causes come forward. Spontaneous full or partial (30-65\%) recovery is seen in a significant number of untreated ISSNHL cases $(9,10)$.

Idiopathic sudden sensorineural hearing loss is an otologic emergency that requires immediate treatment after diagnosis is confirmed. The prognosis of the disease is believed to be better the sooner the treatment is initiated (11). The efficacy of corticosteroids has been demonstrated in many studies (12). Treatment options include systemic and topical steroids, antiviral agents, vasoactive medication and hemodilution, hyperbaric oxygen 
therapy, other modes of medical treatment, and surgical fistula reconstruction, while observation alone is also an option (2).

In our study, we compared the outcomes of the different treatment methods used in the patients followed-up for ISSNHL and aimed to identify the most successful modes of treatment based on the assessment of the prognostic factors, the audiogram types and the time from onset to treatment.

\section{Methods}

The study was conducted at the Otorhinolaryngology Department of the Çanakkale Onsekiz Mart University Research and Application Hospital from February 2009 through January 2015. Written informed consent was obtained from patients if over 18 years of age and from their parents or guardians if younger than 18 years of age. Approval for the study was obtained from the Ethics Committee for Clinical Research of the Çanakkale Onsekiz Mart University School of Medicine (Approval date: 30.10.2014) (Approval No: 2014-19).

Presence of accompanying tinnitus and/or vertigo, systemic disorders, time from onset of hearing loss, otoscopic examination results and hearing status were recorded along with the demographic characteristics of the cases that were treated and followed-up for ISSNHL.

Cases with a history of otologic surgery, recent use of ototoxic drugs, congenital malformation of the inner ear, history of chemoradiotherapy for malignant neoplasia, presence of acute or chronic otitis media, temporal bone fracture, and other neuro-otologic pathologies that explained the hearing loss were excluded from the study. Patients who discontinued the treatment for any reason and who did not receive regular audiologic follow-up were also excluded.

Pure tone audiometry, speech discrimination, tympanometry and stapes reflex tests were routinely performed after anamnesis and otoscopic examination. Data on the severity of the hearing loss, the audiogram type and the time from onset to treatment were recorded. Each ISSNHL patient was electively examined for multiple sclerosis and intracranial tumors with magnetic resonance imaging, especially for pontocerebellar angle pathologies. Biochemical laboratory examinations (including complete blood count, and pre-prandial blood glucose, cholesterol, triglyceride, thyroid-stimulating antibody levels) were performed in regard of patient history and possible diseases.

In each patient, treatment success was assessed based on their hearing gains in pure tone average (PTA). Based on the 2012 clinical practice guideline on sudden hearing loss published by the American Academy of Otolaryngology-Head and Neck Surgery: an improvement of less than $10 \mathrm{~dB}$ HL in PTA was defined as no recovery; an improvement of $10 \mathrm{~dB}$ HL or more in PTA or an improvement of $10 \%$ or more in the speech discrimination score (SDS) was defined as partial recovery; an improvement within the $10 \mathrm{~dB} H \mathrm{HL}$ range of the unaffected ear's hearing threshold and within $5-10 \%$ of its SDS was defined as complete recovery.
Hearing loss was classified as mild if $26-40 \mathrm{~dB}$, moderate if $41-$ $70 \mathrm{~dB}$, severe if 71-90 dB, and profound/complete if $>91 \mathrm{~dB}$. Recovery levels for the different degrees of hearing loss were compared based on the clinical practice guideline.

Effects of distinctly involved frequencies on the prognosis were explored. Audiogram types were compared based on the hearing gains achieved with each treatment method and recovery status (audiogram types are shown in Figure 1).

Time from onset to treatment was grouped as: 1-3 days, day 4-2 weeks, week 2-month 1 , and later than 1 month.

Patients included in the study were grouped as follows based on the treatment they received: Group I: Oral medical treatment, Group II: Oral medical treatment + intratympanic steroid (ITS) therapy, Group III: Oral medical treatment + hyperbaric oxygen therapy, Group IV: ITS therapy.

Treatment methods were compared based on their outcome success and the degree of recovery. The correlation between the time from onset to treatment and the success of the treatment were calculated, and the effects of early treatment on hearing gains were investigated.

Patients who received oral medical treatment for ISSNHL were administered $1 \mathrm{mg} / \mathrm{kg}$ methylprednisolone (Prednol $16 \mathrm{mg} \mathrm{tb}$, Mustafa Nevzat İlaç Sanayi A.Ş.; İstanbul, Turkey) for two to three weeks with incremental dose reductions every three days; acyclovir $400 \mathrm{mg}$ tb 3x1 (Asiviral tb, Terra İlaç ve Kimya Sanayi Ticaret A.Ş.; İstanbul, Turkey) for 7 to 10 days; betahistine dihydrochloride $24 \mathrm{mg}$ tb 2x1 (Betaserc tb, Abbott Laboratuvarları İthalat İhracat Tic. Ltd. Şti.; İstanbul, Turkey) and vitamin B12 tb 1x1 (Nerox B12 tb, Abdi İbrahim İlaç Sanayi ve Ticaret A.Ş.; İstanbul, Turkey) for minimum one month.

Intratympanic steroid was administered to patients in supine position and without using anesthetics. The patient's head was turned to the unaffected side and $0.5 \mathrm{~mL}$ methylprednisolone (Depo-Medrol $40 \mathrm{mg} 1 \mathrm{~mL}$ vial; Pfizer İlaçları Ltd. Şti., İstanbul, Turkey) was injected with a dental needle through the anterosuperior quadrant of the tympanic membrane. To avoid vestibular irritation, the drug was kept in body temperature for 15 to 30 minutes before administration. Following the injection, the patient's head was repositioned and kept at a 45-degree angle on the same side for about 30 minutes to help accumulate the solution around the oval window. Patients were asked to avoid talking, swallowing and moving during and for 20 minutes after the injection. Injections were administered three times at one-week intervals.

All patients were informed in detail about the different treatment methods. One group of patients received only oral medical treatment. One group of patients received only ITS injections because of diabetes mellitus or other comorbidities and the possible systemic side effects of corticosteroids. Another group of patients received oral medical treatment 

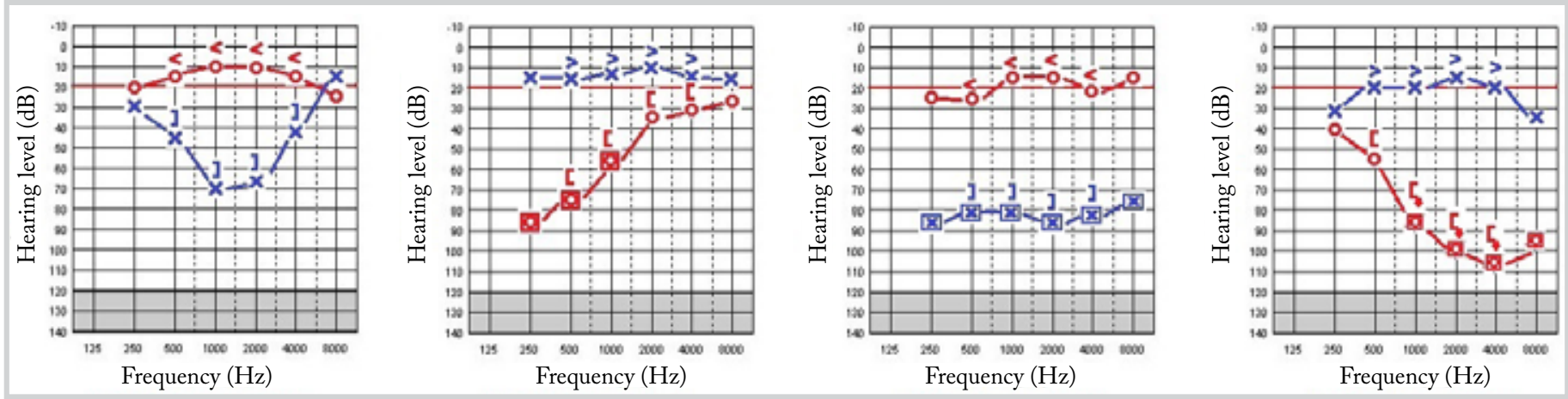

Figure 1. a-d. Audiogram types; (a) bowl type audigram, (b) ascending type audiogram, (c) flat type audiogram (d) descending type audiogram

together with ITS. A group of patients who were treated in the years 2012 through 2014-the years when the Undersea and Hyperbaric Medicine Department of our hospital was active-received oral medical treatment together with hyperbaric oxygen therapy (at a pressure of 2-3 ATA, once a day for 120 minutes for 20 days).

To explore the most successful treatment methods hearing gains were assessed based on two of the most important prognostic factors that affect the success of hearing loss treatment-the time from onset to treatment and the frequencies at which hearing loss was distinct (audiogram types).

\section{Statistical Analysis}

Frequency, mean, standard deviation and minimum-maximum values were calculated for descriptive analysis. Comparative analyses were performed within a confidence interval of $95 \%$ and $\mathrm{p}<0.05$ was accepted as significant. Two independent groups were compared with the Independent Samples $t$ test if continuous variables followed a normal distribution and with the Mann-Whitney U test if they followed a non-normal distribution. To compare more than two groups, the one-way variance analysis (ANOVA) was used if a normal distribution was present, and the Kruskal-Wallis test was used if a non-normal distribution was present. Spearman's correlation was used to calculate the correlations among the continuous variables. The Chi-square test was used to identify the level of correlation among two or more qualities. All statistical analyses were performed using the Statistical Package for the Social Sciences version 19.0 (IBM Corp.; NY, USA) package.

\section{Results}

The patients included in the study were aged between 14 and 81 years (mean $46.83 \pm 14.76$ years). $49 \%$ were male $(54.4 \%)$ and $41 \%$ were female $(45.6 \%)$. On the average patients were followed up for six months after their treatment was initiated (min 3 weeks, max 9 months). Group I was comprised of 17 patients (18.9\%), Group II of 35 patients (38.9\%), Group III of 16 patients (17.8\%), and Group IV of 22 patients (24.4\%).

Baseline audiograms of patients showed mild hearing loss in 21 patients $(23.3 \%)$, moderate hearing loss in 33 patients (36.7\%), severe hearing loss in 9 patients (10\%), and profound hearing loss in 27 patients (30\%).
Review of audiogram types showed descending type hearing loss in 20 patients (22.2\%), ascending type in 19 patients (21.1\%), bowl type in 6 patients (6.7\%), and flat type in 45 patients (50\%).

Regarding the time from onset to treatment, this period was 1 to 3 days in 32 patients (35.5\%), 4 days to 2 weeks in 36 patients (40\%), 2 weeks to 1 month in 16 patients (17.8\%), and longer than 1 month in 6 patients (6.7\%).

In-depth anamneses of patients revealed hearing loss + vertigo in 20 patients $(22.2 \%)$, hearing loss + tinnitus in 63 patients (70\%), and hearing loss + tinnitus + vertigo in 18 patients (20\%). Thirty-five patients (38.9\%) were identified to have a systemic disease.

Regarding treatment success, the mean hearing gain of the 90 patients included in the study was found $17.35 \mathrm{~dB}$ in pure tone audiometry following their treatment. When reviewed based on the ISSNHL clinical practice guideline, 29 patients (32.2\%) were seen to have achieved complete recovery, 26 patients (28.9\%) partial recovery, and 35 patients (38.9\%) no recovery.

No statistically significant differences were identified in terms of the mean hearing gains provided by the four treatment methods employed $(\mathrm{p}=0.678)$ (Mean hearing gains: Group I: 14.76 \pm 20.26 , Group II: $15.94 \pm 18.84$, Group III: $20.18 \pm 24.79$, Group IV: $19.54 \pm 19.20 \mathrm{~dB}$

When recovery status was examined based on the degree of hearing loss, the rate of complete recovery was seen to decrease significantly as the severity of the hearing loss increased $(p<0.05)$. Complete recovery rates were found to be $57.2 \%$ in mild hearing loss, $42.4 \%$ in moderate hearing loss, $33.3 \%$ in severe hearing loss, and $0 \%$ in profound/complete hearing loss.

When treatment success was reviewed based on the baseline audiogram types of patients, mean hearing gain was identified to significantly differ among the groups $(\mathrm{p}=0.018)$. Mean hearing gain was lower in cases with a descending type audiogram $(\mathrm{p}=0.014)($ Table 1$)$.

When treatment success was reviewed based on the times from onset to treatment, mean hearing gain was identified to signifi- 
cantly differ among the groups ( $\mathrm{p}=0.025)$. Mean hearing gain was lower in patients who received their first treatment at least one month after onset $(\mathrm{p}=0.035)$ (Table 2).

Review by recovery status showed that the rate of complete recovery was higher in cases with shorter times from onset to treatment and the rate of no recovery was lower (Table 3). Spearman's correlation analysis between the time from onset to treatment and the recovery status demonstrated a moderate inverse correlation (correlation coefficient $-0.290, \mathrm{p}=0.005$ ), and recovery rates were seen to significantly decrease as the time from onset to treatment increased.

No statistically significant differences were identified in terms of the gains achieved in pure tone average when patient data were reviewed by age in two groups, with one group including patients aged under 40 years and one group including patients aged over 40 years $(\mathrm{p}=0.284)$. The correlation coefficient between treatment success and patient age was $0.054(\mathrm{p}=0.615)$ and no statistically significant correlation was assessed.

With respect to pure tone average, hearing gains were found $15.51 \mathrm{~dB}$ in males and $19.56 \mathrm{~dB}$ in females, with no statistically significant difference between the genders $(\mathrm{p}=0.284)$. Statistical analysis demonstrated that a presence of tinnitus $(\mathrm{p}=0.754)$ and/

Table 1. Success of treatment according to the type of audiogram

\begin{tabular}{l|c|c|c}
\hline & $\begin{array}{c}\text { Minimum } \\
\text { hearing } \\
\text { gain (dB) }\end{array}$ & $\begin{array}{c}\text { Maximum } \\
\text { hearing } \\
\text { gain (dB) }\end{array}$ & $\begin{array}{c}\text { Mean } \\
\text { hearing } \\
\text { gain } \pm \text { SD }\end{array}$ \\
\hline Audiogram type & -13 & 35 & $6.8 \mathrm{~dB} \pm 13.16$ \\
\hline $\begin{array}{l}\text { Descending } \\
\text { (higher frequencies) }\end{array}$ & -24 & 62 & $24.8 \mathrm{~dB} \pm 20.45$ \\
\hline $\begin{array}{l}\text { Ascending } \\
\text { (lower frequencies) }\end{array}$ & 5 & 52 & $22.3 \mathrm{~dB} \pm 22.51$ \\
\hline $\begin{array}{l}\text { Bowl } \\
\text { (mid-frequencies) }\end{array}$ & -23 & 80 & $18.8 \mathrm{~dB} \pm 21.08$ \\
\hline $\begin{array}{l}\text { Flat } \\
\text { (all frequencies) }\end{array}$ & & & 0.018 \\
\hline \begin{tabular}{l} 
p \\
\hline statistics: variance analysis \\
dB: decibel; SD: standard deviation
\end{tabular} & & & \\
\hline
\end{tabular}

or vertigo $(\mathrm{p}=0.865)$ together with hearing loss and the presence of a diagnosed systemic disease $(p=0.186)$ did not negatively affect treatment success.

No statistically significant differences were identified among the audiogram types with respect to the mean hearing gains achieved with different treatment methods (Table 4).

When mean hearing gain was examined based on the time from onset to treatment, no statistically significant differences were identified in terms of the mean hearing gains achieved with different treatment methods within different time frames (Table 5).

A mean hearing gain of $20.3 \mathrm{~dB}$ and of $7 \mathrm{~dB}$ were identified, respectively, in patients who received hyperbaric oxygen therapy and ITS in addition to oral medical treatment. While higher hearing gains were seen with hyperbaric oxygen therapy, no statistically significant differences were identified due to the low number of cases $(\mathrm{p}=0.182)$.

When treatment methods were examined based on the audiogram types and the times from onset to treatment, oral medical treatment + hyperbaric oxygen therapy was found to have achieved the highest success in all audiogram types after week 2 .

\section{Discussion}

While in general normal hearing is recovered in one-third of the ISSNHL cases, speech reception threshold (SRT) remains at $40-80 \mathrm{~dB}$ in one-third of the cases. The remaining cases experience complete hearing loss (9). Of the 90 patients included in our study, 35 (38.9\%) achieved no recovery, 26 (28.9\%) achieved partial recovery, and $29(32.2 \%)$ achieved complete recovery.

Early diagnosis and early treatment are known to positively affect the prognosis in ISSNHL (11). While complete recovery rates were higher in cases with shorter times from onset to treatment, the number of cases with no recovery were significantly lower ( $\mathrm{p}=0.039)$. Our study has demonstrated that the time from onset to treatment is a significant factor in the prognosis of the condition.

Wilson et al. (10) reported that whereas mild ISSNHL cases showed a tendency for spontaneous recovery, and moderate and

Table 2. Treatment success according to the onset of treatment

\begin{tabular}{|c|c|c|c|c|}
\hline & & Minimum hearing gain $(\mathrm{dB})$ & Maximum hearing gain $(\mathrm{dB})$ & Mean hearing gain \pm SD \\
\hline \multicolumn{5}{|c|}{ Time from onset to treatment No. patients } \\
\hline $1-3$ days & 32 & -23 & 74 & $22.78 \mathrm{~dB} \pm 21.18$ \\
\hline $4^{\text {th }}$ day -2 weeks & 36 & -24 & 80 & $18.5 \mathrm{~dB} \pm 21.04$ \\
\hline $2^{\text {nd }}$ week $-1^{\text {th }}$ month & 16 & -13 & 36 & $10.81 \mathrm{~dB} \pm 13.25$ \\
\hline After 1 month & 6 & -10 & 9 & $-1.00 \mathrm{~dB} \pm 7.58$ \\
\hline $\mathrm{p}$ & & & & 0.025 \\
\hline
\end{tabular}


severe cases responded well to steroid therapy, profound and complete loss cases had poor recovery. In our study, we identified that complete recovery rates decreased significantly as the severity of the hearing loss increased $(\mathrm{p}=0.001)$.

Of the ISSNHL cases, $40-50 \%$ present with vertigo and 60 $75 \%$ with tinnitus. Patients who present with vertigo, nystagmus and abnormal electronystagmography (ENG) findings usually have a poorer prognosis. In their study, Kaplan et al. (13) reported that vertigo reduced the recovery rates; however, the authors reported to have found no significant correlation between tinnitus and ISSNHL in terms of recovery rates. In our study, a comparison between the cases who at baseline reported of hearing loss and the cases who reported of tinnitus and/or vertigo

Table 3. Recovery status according to the time from onset to treatment

\begin{tabular}{lr|c|c|c}
\hline & $\begin{array}{c}\text { No } \\
\text { recovery }\end{array}$ & $\begin{array}{c}\text { Partial } \\
\text { recovery }\end{array}$ & $\begin{array}{c}\text { Complete } \\
\text { recovery }\end{array}$ \\
\hline Time from onset to treatment & $\mathbf{N}$ & $\mathbf{N} / \%$ & N/\% & N/\% \\
\hline 1-3 days & 32 & $8 / 25$ & $10 / 31.3$ & $14 / 43.8$ \\
\hline $4^{\text {th }}$ day - 2 weeks & 36 & $14 / 38.8$ & $11 / 30.6$ & $11 / 30.6$ \\
\hline $2^{\text {th }}$ week - $1^{\text {st }}$ month & 16 & $7 / 43.8$ & $5 / 31.3$ & $4 / 25$ \\
\hline After 1 month & 6 & $6 / 100$ & $-/-$ & $-/-$ \\
\hline N: number of patients; \%: percentage of patients & &
\end{tabular}

symptom in addition to hearing loss, showed comparable mean hearing gains after treatment and did not reveal any statistically significant differences $(p>0.05)$.

The prognosis is poorer in children and adults younger than 40 years of age (9). In our study, while hearing gains were lower in patients younger than 40 years of age, no statistically significant differences were identified between the two age groups $(\mathrm{p}=0.284)$.

Hearing losses that involve lower frequencies achieve better recovery than those that involve higher frequencies (9). In our study, a comparison of the mean hearing gains achieved in cases which hearing loss distinctly involved low, medium, high levels of frequencies, and all levels of frequencies showed that cases which affected higher frequencies achieved statistically lower gains compared to the other groups $(\mathrm{p}=.014)$. These data support that prognosis is poorer in cases with higher hearing loss and higher frequency involvement.

A summary of the studies reported in the literature comparing systemic steroid, ITS and combined therapies are given in Table 7 (14-19). In our study, ITS therapy by itself and in addition to oral medical treatment were seen to achieve higher hearing gains; however, statistical analysis showed no significant differences in the hearing gains provided by the treatment methods or the degree of recovery $(p>0.05)$.

Table 4. Mean hearing gains according to the treatment methods and audigram types

\begin{tabular}{|c|c|c|c|c|c|c|c|c|c|}
\hline \multirow{3}{*}{$\begin{array}{l}\text { Treatment method } \\
\text { Group I: Oral medical therapy }\end{array}$} & \multicolumn{9}{|c|}{ Audiogram type } \\
\hline & \multicolumn{2}{|c|}{ Descending } & \multicolumn{2}{|c|}{ Ascending } & \multicolumn{2}{|c|}{ Bowl } & \multicolumn{2}{|c|}{ Flat } & \multirow{2}{*}{$\begin{array}{c}\mathrm{p} \\
0.075\end{array}$} \\
\hline & PTA & $\mathrm{N}$ & PTA & $\mathrm{N}$ & PTA & $\mathrm{N}$ & PTA & $\mathrm{N}$ & \\
\hline & $-5 \mathrm{~dB}$ & 3 & $26 \mathrm{~dB}$ & 6 & $5 \mathrm{~dB}$ & 1 & $15 \mathrm{~dB}$ & 7 & \\
\hline Group II: Oral medical therapy + intratympanic steroid & $9 \mathrm{~dB}$ & 13 & $23 \mathrm{~dB}$ & 9 & - & & $18 \mathrm{~dB}$ & 13 & 0.780 \\
\hline Group III: Oral medical therapy + hyperbaric $\mathrm{O}_{2}$ & $4,5 \mathrm{~dB}$ & 6 & $41 \mathrm{~dB}$ & 2 & - & & $26.75 \mathrm{~dB}$ & 8 & 0.066 \\
\hline Group IV: Only intratympanic steroid & $27 \mathrm{~dB}$ & 1 & $19 \mathrm{~dB}$ & 4 & $25.8 \mathrm{~dB}$ & 5 & $16.5 \mathrm{~dB}$ & 12 & 0.780 \\
\hline $\mathrm{p}$ & \multicolumn{2}{|c|}{0.150} & \multicolumn{2}{|c|}{0.620} & \multicolumn{2}{|c|}{$0.333^{* * *}$} & \multicolumn{2}{|c|}{0.693} & \\
\hline
\end{tabular}

Statistics; Kruskal Wallis test (*** Mann Whitney test)

PTA: hearing gains in pure tone average; $\mathrm{N}$ : number of patients; $\mathrm{dB}$ : decibel; $\mathrm{O}_{2}$ : oxygen

Table 5. Mean hearing gain according to treatment methods and time from onset to treatment

Time from onset to treatment

\begin{tabular}{|c|c|c|c|c|c|c|c|c|c|}
\hline \multirow[t]{2}{*}{ Treatment method } & \multicolumn{2}{|c|}{ 1-3 days } & \multicolumn{2}{|c|}{$4^{\text {th }}$ day -2 weeks } & \multicolumn{2}{|c|}{$2^{\text {nd }}$ week - 1 month } & \multicolumn{2}{|c|}{ After 1 month } & \multirow[t]{2}{*}{$\mathrm{p}$} \\
\hline & PTA & $\mathrm{N}$ & PTA & $\mathrm{N}$ & PTA & $\mathrm{N}$ & PTA & $\mathrm{N}$ & \\
\hline Group I: Oral medical therapy & $21 \mathrm{~dB}$ & 7 & $20 \mathrm{~dB}$ & 4 & $11.66 \mathrm{~dB}$ & 3 & $3.66 \mathrm{~dB}$ & 3 & 0.298 \\
\hline Group II: Oral medical therapy + intratympanic steroid & $20.16 \mathrm{~dB}$ & 12 & $17.86 \mathrm{~dB}$ & 15 & $6.85 \mathrm{~dB}$ & 7 & $0.00 \mathrm{~dB}$ & 1 & 0.177 \\
\hline Group III: Oral medical therapy + hyperbaric $\mathrm{O}_{2}$ & $20.5 \mathrm{~dB}$ & 2 & $24.87 \mathrm{~dB}$ & 8 & $16 \mathrm{~dB}$ & 5 & $3 \mathrm{~dB}$ & 1 & 0.778 \\
\hline Group IV: Only intratympanic steroid & $27.18 \mathrm{~dB}$ & 11 & $13.22 \mathrm{~dB}$ & 9 & $10 \mathrm{~dB}$ & 1 & $2 \mathrm{~dB}$ & 1 & 0.101 \\
\hline $\mathrm{p}$ & \multicolumn{2}{|c|}{0.513} & \multicolumn{2}{|c|}{0.702} & \multicolumn{2}{|c|}{0.907} & \multicolumn{2}{|c|}{0.794} & \\
\hline
\end{tabular}

Statistics; Kruskal Wallis test

PTA: hearing gains in pure tone average; $\mathrm{N}$ : number of patients; $\mathrm{dB}$ : decibel; $\mathrm{O}_{2}$ : oxygen 
In our study, the hearing gains achieved with only ITS therapy was found comparable to the gains achieved with the other treatment methods. Partial/complete recovery rates achieved with only ITS therapy were also comparable to those of the other treatment methods. Therefore, this treatment method comes forward in cases which a systemic therapy is contraindicated or in patients with low multi-drug tolerance or in the presence of a systemic disease.

Among the four treatment methods employed in our study, the group which received oral medical treatment + hyperbaric oxygen therapy was assessed to have achieved the highest hearing gains; however, no statistically significant differences were identified for this treatment method versus the other methods $(\mathrm{p}<0.05)$. In the literature, Fattori et al. (20) report to have compared the hyperbaric oxygen therapy and the intravenous vasodilator therapy and found the hyperbaric oxygen therapy to be more effective. Having compared hyperbaric oxygen therapy with the standard treatment protocol (prednisolone, rheomacrodex, diazepam and pentoxifylline) in their study, Topuz et al. (21) have assessed higher efficacy with the hyperbaric oxygen therapy. Naiboğlu et al. (22) suggest that better outcomes could be achieved in ISSNHL patients when ITS therapy is added to systemic steroid and hyperbaric oxygen therapy.

\section{Conclusion}

In our study, we identified the time from onset to treatment, the severity of the hearing loss, and the type of the audiogram as the major factors that affect the prognosis in ISSNHL. Unlike the reports in the literature, accompanying vertigo and tinnitus, and presence of a systemic disease were not found to negatively affect the prognosis.

No statistically significant differences were identified with respect to the treatment methods employed, the mean hearing gains achieved with the treatment methods and the recovery status. Similar to the literature, higher recovery rates were seen with combined steroid therapy (oral medical treatment + ITS therapy) compared to the oral steroid therapy alone, but no statistically significant differences were identified among these methods. An ITS therapy by itself offers benefits in terms of avoiding systemic side-effects, providing shorter hospitalization times, as well as ease of administration.

While we observed that partial/complete recovery rates were highest within the first two weeks, whether by treatment or by spontaneous recovery, we believe, based on our study data and clinical experiences, that hyperbaric oxygen therapy will be a more effective treatment after this time frame. We believe that identifying the most successful treatment methods with respect

Table 6. The most successful treatment methods according to audiogram type and time from onset to treatment

Time from onset to treatment

\begin{tabular}{|c|c|c|c|c|}
\hline Odyogram tipi & 1-3 days & $4^{\text {th }}$ day -2 weeks & $2^{\text {nd }}$ week - $1^{\text {st }}$ month & After 1 month \\
\hline $\begin{array}{l}\text { Descending } \\
\text { (higher frequencies) }\end{array}$ & Only ITS & $\begin{array}{l}\text { Oral medical therapy + } \\
\text { ITS }\end{array}$ & $\begin{array}{c}\text { Oral medical therapy + } \\
\text { hyperbaric } \mathrm{O}_{2}\end{array}$ & $\begin{array}{c}\text { Oral medical therapy + } \\
\text { hyperbaric } \mathrm{O}_{2}\end{array}$ \\
\hline $\begin{array}{l}\text { Ascending } \\
\text { (lower frequencies) }\end{array}$ & Only ITS & $\begin{array}{c}\text { Oral medical therapy + } \\
\text { hyperbaric } \mathrm{O}_{2}\end{array}$ & $\begin{array}{c}\text { Oral medical therapy + } \\
\text { hyperbaric } \mathrm{O}_{2}\end{array}$ & - \\
\hline $\begin{array}{l}\text { Bowl } \\
\text { (mid-frequencies) }\end{array}$ & Only ITS & Only ITS & - & - \\
\hline $\begin{array}{l}\text { Flat } \\
\text { (All frequencies) }\end{array}$ & $\begin{array}{c}\text { Oral medical therapy } \\
+ \text { ITS }\end{array}$ & $\begin{array}{l}\text { Oral medical therapy + } \\
\text { hyperbaric } \mathrm{O}_{2}\end{array}$ & $\begin{array}{c}\text { Oral medical therapy + } \\
\text { hyperbaric } \mathrm{O}_{2}\end{array}$ & $\begin{array}{c}\text { Oral medical therapy + } \\
\text { hyperbaric } \mathrm{O}_{2}\end{array}$ \\
\hline
\end{tabular}

ITS: intratympanic steroid; $\mathrm{O}_{2}$ : oxygen

Table 7. Review of literature

\begin{tabular}{|c|c|c|}
\hline Literature & Compared treatment methods & Results \\
\hline Plontke et al. (14) & ITS and control group for salvage therapy & İTS>Placebo \\
\hline Battaglia et al. (15) & $\begin{array}{l}\text { İT dexametason }+ \text { high dose prednisolon } \\
\text { and only prednisolon }\end{array}$ & Combined therapy $>$ Systemic prednisolon \\
\hline Rauch etal. (16) & Oral prednisolon and ITS & Oral prednisolon $=$ ITS \\
\hline Arastou et al. (17) & $\begin{array}{l}\text { Systemic prednisolon and systemic } \\
\text { prednisolon with IT dexametason }\end{array}$ & Combined therapy $>$ Systemic prednisolon \\
\hline Gündoğan et al. (18) & Combined ITS + oral therapy and only oral steroid & Combined therapy>Only oral steroid \\
\hline Kim et al. (19) & $\begin{array}{l}\text { Combined ITS + oral therapy and } \\
\text { only systemic steroid and only ITS }\end{array}$ & $\begin{array}{c}\text { Combined therapy>Only systemic } \\
\text { steroid=Only ITS }\end{array}$ \\
\hline
\end{tabular}


to the involved frequencies and the time from onset to treatment will provide guidance to physicians in the treatment of ISSNHL.

Ethics Committee Approval: Ethics committee approval was received for this study from Çanakkale Onsekiz Mart University School of Medicine Clinical Investigation Ethics Committee (30.10.2014) (Decision Nr:2014-19).

Informed Consent: Written informed consent was obtained from patients and the parents of the patients under 18-year-old who participated in this study.

Peer-review: Externally peer-reviewed.

Author Contributions: Concept - T.T, H.E., Ö.Ç., O.G., F.S.D.; Design - T.T, H.E., Ö.Ç., O.G., F.S.D.; Supervision - T.T, H.E., Ö.Ç., O.G., F.S.D.; Resource - T.T., F.S.D., Ö.Ç.; Materials - T.T., F.S.D.; Data Collection and/or Processing - T.T., Ö.Ç., H.E.; Analysis and/ or Interpretation - T.T., F.S.D., O.G.; Literature Search - T.T., F.S.D.; Writing - T.T., F.S.D.; Critical Reviews - F.S.D., O.G., Ö.Ç.

Conflict of Interest: The authors have no conflicts of interest to declare.

Financial Disclosure: The authors declared that this study has received no financial support.

\section{References}

1. Lamm K, Lamm C, Arnold W. Effect of isobaric oxygen versus hyperbaric oxygen on the normal and noise damaged hypoxic and ischemic guinea pig inner ear. Adv Otorhinolaryngol 1998; 54 : 59-85. [CrossRef]

2. Stachler RJ, Chandrasekhar SS, Archer SM, Rosenfeld RM, Schwartz SR, Barrs DM, et al. Clinical practice guideline: Sudden hearing loss. Otolaryngol Head Neck Surg 2012; 146(3 Suppl): 1-35. [CrossRef]

3. Lazarini PR, Camargo AC. İdiopathic sudden sensorineural hearing loss: Etiopathogenic aspects. Braz J Otorhinolaryngol 2006; 72: 554-61. [CrossRef]

4. Shikowitz MJ. Sudden sensorineural hearing loss. Med Clin North Am 1991; 75: 1239-50. [CrossRef]

5. Haberkamp TJ, Tanyeri HM. Management of idiopathic sudden sensorineural hearing loss. Am J Otol 1999; 20: 587-92.

6. Shaia F, Sheehy J. Sudden sensorineural hearing impairment: A report of 1,220 cases. Laryngoscope 1976; 86: 389-98. [CrossRef]

7. Vasama JP, Linthicum FH Jr. Idiopathic sudden sensorineural hearing loss: Temporal bone histopathologic study. Ann Otol Rhinol Laryngol 2000; 109: 527-32. [CrossRef]
8. Desloovere C, Knecht R, Germonpre P. Hyperbaric oxygen therapy after failure of conventional therapy for sudden deafness. B-ENT 2006; 2: 69-73.

9. Mattox DE, Simmons FB. Natural history of sudden sensorioneural hearing loss. Ann Otol 1977; 86: 463-80.

10. Wilson WR, Byl FM, Laird N. The efficacy of steroids in the treatment of idiopathic sudden hearing loss: A double-blind clinical study. Arch Otolaryngol 1980; 106: 772-6. [CrossRef]

11. Uysal İO, Müderris T, Polat K, Yüce S, Gültürk S. Is the time from the onset to the treatment a prognostic indicator for hearing recovery in idiopathic sudden sensorineural hearing loss?. Kulak Burun Bogaz Ihtis Derg 2015; 25: 70-6. [CrossRef]

12. Chen CY, Halpin C, Rauch SD. Oral steroid treatment of sudden sensorineural hearing loss: a ten year retrospective analysis. Otol Neurotol 2003; 24: 728-33. [CrossRef]

13. Kaplan Y, Ülkümen B, Kanlıkama M. Evaluation of prognostic factors in sudden hearing loss. J Kartal TR 2012; 23: 84-90. [CrossRef]

14. Plontke S, Löwenheim H, Preyer S, Leins P, Dietz K, Koitschev A, et al. Outcomes research analysis of continuous intratympanic glucocorticoid delivery in patients with acute severe to profound hearing loss: Basis for planning randomized controlled trials. Acta Otolaryngol 2005; 125: 830-9. [CrossRef]

15. Battaglia A, Burchette R, Cueva R. Combination therapy (intratympanic dexamethasone + high-dose prednisone taper) for the treatment of idiopathic sudden sensorineural hearing loss. Otol Neurotol 2008; 29: 453-60. [CrossRef]

16 Rauch SD, Halpin CF, Antonelli PJ, Babu S, Carey JP, Gantz BJ, et al. Oral vs intratympanic corticosteroid therapy for idiopathic sudden sensorineural hearing loss. A randomized trial. JAMA 2011; 305: 2071-9. [CrossRef]

17. Arastou S, Tajedini A, Borghei P. Combined intratympanic and systemic steroid therapy for poor-prognosis sudden sensorineural hearing loss. Iran J Otorhinolaryngol 2013; 25: 23-8.

18. Gundogan O, Pınar E, Imre A, Ozturkcan S, Cokmez O, Yigiter A. Therapeutic efficacy of the combination of intratympanic methylprednisolone and oral steroid for idiopathic sudden deafness. Otolaryngol Head Neck Surg 2013; 149: 753-8. [CrossRef]

19. Kim SH, Jung SY, Kim MG, Byun JY, Park MS, Yeo SG. Comparison of steroid administration methods in patients with idiopathic sudden sensorineural hearing loss: a retrospective observational study. Clin Otolaryngol 2015; 40: 183-90. [CrossRef]

20. Fattori B, Berrettini S, Casani A, Nacci A, De Vito A, De Iaco G. Sudden hypoacusis treated with hyperbaric oxygen therapy: A controlled study. Ear Nose Throat J 2001; 80: 655-60.

21. Topuz E, Yigit O, Cinar U, Seven H. Should hyperbaric oxygen be added to treatment in idiopathic sudden sensorineural hearing loss?. Eur Arch OtorhinoLaryngol 2004; 261: 393-6. [CrossRef]

22. Naiboğllu B, Külekçi S, Sürmeli M, Verim A, Kalaycik Ertugay Ç, İhvan Ö, et al. Efficacy of multimodality approach to sudden hearing loss. Kulak Burun Bogaz Ihtis Derg 2015; 25: 77-81. [CrossRef] 